\title{
Trivia
}

\section{Cumulative trivia: a holistic conceptualization of the minor problems of ageing}

\author{
Elinor Newall, Belinda Dewar, Marti Balaam, Mike Porter, Sarah Baggaley, Scott Murray and \\ Alan Gilloran Queen Margaret University College, Edinburgh, UK
}

\begin{abstract}
In 1999 Hockey postulated the hypothesis that some older people experience a continual accumulation of small, individually minor events or difficulties that degrade their resilience until they 'cannot cope with another thing'. She referred to this accumulation as cumulative trivia. The essence of cumulative trivia lies in their everyday nature, where regular occurrence and variety of challenge stack up to form perceived threats to an older person's ability to function independently. There is a strong overlap between this concept of cumulative trivia and an established concept in the health psychology literature called daily hassles. Consistent with the mainstream psychology approach, the vast majority of research into daily hassles has been quantitative. In the present article we adopt a critical stance to the knowledge produced from this research, questioning its foundations in the positivist epistemology. In particular the research is criticized for absenting the social context from our understanding of daily hassles, and for focusing too strongly upon the individual. The considerable lack of research into daily hassles in the lives of older people is also highlighted, indicating the need for work in this area. Using a social constructionist framework, we attempt to develop a holistic conceptualization of cumulative trivia, through which some key differences between the cumulative trivia and daily hassles concepts are indicated. We argue that cumulative trivia could be seen within the framework of the daily hassles literature but that this framework would require to be developed further and refined to accommodate the specific characteristics associated with Hockey's concept. We suggest that the social construction of ageing may serve to normalize experiences in ageing such that they become trivialized. Finally we examine how the social construction of independence as an ideal state may create or exacerbate the effects of cumulative trivia, and argue for its reconstruction to legitimize older people's experiences of minor difficulties. Through these arguments we relocate responsibility for cumulative trivia toward the social context.
\end{abstract}

Key words: cumulative trivia; daily hassles; health and social care; independence; older people; social constructionism

Received: January 2006; accepted: March 2006

\section{Introducing the cumulative trivia concept}

The aim of this article is to introduce a concept postulated by Hockey in a personal communication to

Address for correspondence: Professor Alan Gilloran, Vice Principal (Research Development), Queen Margaret University College, Corstorphine Campus, Clerwood Terrace, Edinburgh, EH12 8TA, UK. Email: agilloran@qmuc.ac.uk

(C) 2006 Cambridge University Press staff at the Queen's Nursing Institute, Scotland, called cumulative trivia (Hockey, 1999, cited in Balaam et al., 2001). The cumulative trivia hypothesis holds that some older people may experience a continual accumulation of small, individually minor events or difficulties that degrade their resilience until they 'cannot cope with another thing' (Hockey, 1999, cited in Balaam et al., 2001). Older people experience a number of small problems in 
their day-to-day life, many of which may be produced or exacerbated by older age. The 'trivia' of cumulative trivia refer to these small, seemingly minor events or difficulties. 'Trivia' will often be activities that were previously sources of pleasure or tasks that were undertaken with ease or minimal effort. As a consequence of increasing age, however, they can become more difficult to negotiate. Individually or in small doses these trivia might be coped with successfully without incurring too great a struggle. However, if they are allowed to accumulate over time, Hockey argued that they would wear down an older person's resilience and exhaust their coping resources.

\section{Examples of cumulative trivia}

Many of the difficulties that constitute trivia may be everyday tasks or activities. Consequently, trivia may be particularly threatening to independence because they occur regularly, and because there are a number of different trivia that must be dealt with. In describing her cumulative trivia hypothesis to the authors, Hockey identified as an example the difficulty she experienced in pushing open the very heavy door that stood between her home and the outside world. The effort involved in completing this seemingly trivial task was such that she felt increasingly disinclined to leave her home. Hockey felt that small difficulties of this nature were piling up in her life, to a point where she feared she could lose her independence. Any one instance of trivia would not individually be expected to threaten independence. It is likely though that an older person will experience a number of these difficulties in their day-today lives, often on a daily basis. The continual investment of precious energy and the repeated feelings of upset, frustration or fear when tasks become unmanageable may become overwhelming, particularly if help is limited or absent.

To illustrate the concept further, let us provide some examples of 'trivia'. Changing a light bulb is a simple task that may become increasingly difficult with older age. An older person may be unable to stretch up and reach the light bulb to change it or they may lack the balance to safely stand on stepladders. An additional frustration in having to change light bulbs is the degree of strength and manual dexterity which is required. The difficulty experienced with this task may incur feelings of upset or frustration, particularly because it used to be conducted with ease. The nature of the task is also such that one cannot predict when the bulb will go, and so it may not always be possible to find someone who can help when the bulb needs changed. A frightening, and not unrealistic consequence may be that, unable to change the bulb, the older person ignores it and copes until the day he or she trips and falls in a poorly lit area of their home. A study by Clark et al. (1998) provides a further example of trivia. These authors noted that changing net curtains was a very important household task for older women. This task had particular significance because it was a public and private demonstration of one's respectability and ability to manage. A great deal of physical effort could be invested in this task to ensure it was completed. Clark et al. described one older woman who had recently had a fall, and who could not now take the risk of changing the nets and hurting herself again. She wept at the state of her curtains, distressed that they were 'filthy'. She felt that the dirty curtains indicated to the outside world that she was not making the effort, or that she was not managing her home. The examples of trivia provided indicate that their impact can occur at the physical, psychological and social levels of an older person's life.

Further examples, such as fastening buttons or fetching the morning paper, could be provided but the crucial defining feature is that each example in itself does not represent a crisis. Consequently it is the accumulation of a number of these instances and the growing number that are left unresolved which causes a problem in coping rather than one single show-stopping event.

\section{Minor difficulties of older age are trivialized}

Hockey used the term 'trivia', in part, to underline that the problems referred to were individually minor but that their accumulation poses a threat for many older people in relation to their sense of independence. The term 'trivia' was also used to indicate that the significance of these small difficulties can be underplayed and thus trivialized. The example of dirty net curtains is apposite; while this problem might be viewed by many younger people as relatively insignificant, it is clear that it has real importance to the older people interviewed 
by Clark in 1998. Problems may also be trivialized by older people themselves. For example, they may think that they can do without a particular light, that it does not really matter and that it will not significantly affect their lives, until of course it is too late.

There is also evidence that professionals working in health and social care may fail to appreciate the significance of certain problems experienced by older people instead dismissing them as a normal part of ageing. Stevenson (1989) has noted that professionals may underestimate and therefore trivialize the problems of ageing. In a description that aptly portrays the cumulative trivia hypothesis, Stevenson has likened the impact of these problems to Chinese water torture, gradually wearing the older person down:

$\ldots$ in the nature of things, old people spend much more time indoors. Not surprisingly the defects in dwellings or the equipment on which they depend loom large. They suffer more, as a result, both physically and emotionally - the dripping tap drips on the emotions, like Chinese torture. Those who work with older people may have noticed that these (sometimes apparently trivial) domestic problems create anger and despair when they cannot be resolved. They bring home dependency - in a painful way (p. 118).

As the quote illustrates, older people who spend much time in their homes often have to face the need for minor repairs to the building or to household items which they cannot manage. Moreover they are literally faced with these reminders of their own incapacity on a daily basis. The choice is to ask for assistance from a service provider, who may perceive the task as trivial, or from a friend or relative who may arrive at the same conclusion. Either way, having to ask another to perform the task creates a sense of dependency. The emotional impact of cumulative trivia is that ultimately these problems indicate a progression towards increasing dependence.

We recognize that there is little empirical evidence to substantiate the concept of 'cumulative trivia'. Indeed one specific aim of this article is to prompt further debate and empirical research in this area. The concept of 'cumulative' may for some people represent only a small number of trivial occurrences, whereas for others this number may be significantly greater. The point, however, is the meaning that these accumulated trivial occurrences take on for any particular older person within the social context of their lives and specifically in relation to their sense of independence.

On the basis of a personal communication to staff at the Queen's Nursing Institute, Scotland, Hockey verbally presented the cumulative trivia hypothesis to a research team in 1999, and in 2001, with financial support from QNIS, the team conducted an extensive literature review to determine whether the concept of cumulative trivia existed in the literature (Balaam et al., 2001). Our search did not discover any use of the terms 'Cumulative Trivia' or 'Cumulative Trivia Syndrome', but the daily hassles concept was identified and recognized to have a strong overlap with the cumulative trivia concept. Having introduced cumulative trivia, we turn now to a consideration of daily hassles.

\section{Description and critique of the daily hassles concept}

The daily hassles concept emerged from a largescale research project in America, The Berkeley Stress and Coping project, during the 1980s (Lazarus, 1999). The term 'daily hassles' was coined by Lazarus and colleagues to describe: 'the irritating, frustrating, distressing demands that to some degree characterize everyday transactions with the environment' (Larzarus, 1999). Original work by Holmes and Rahe (1967) suggested that major life events were a significant source of stress that was related to health. However, research by Kanner et al. (1980) and later work by Monroe (1983) indicated that daily hassles were a better predictor of psychological symptoms than major life events, with daily hassles explaining a greater amount of the variance in symptoms. Over time daily hassles have become an established measure of stress in the psychology literature (Rowlinson and Felner, 1988).

\section{Mediators and moderators of daily hassles}

The most prominent model of stress into which daily hassles fits is Lazarus's 'transactional' model, central to which is the concept of appraisal. This 
model holds that stress occurs as a transaction between the individual and her/his environment. A stress response is elicited when something in the environment is appraised as stressful by the individual. Two forms of appraisal are involved in this transaction: primary and secondary. The former refers to whether the hassle is perceived as benign or harmful. The latter refers to the individual's judgment of whether she/he feels sufficiently able to cope with the hassle. A stress response is contingent on the result of this appraisal process (Lazarus, 1999). A number of mediating and moderating factors have emerged in the literature, which affect these appraisal processes. For example, hardiness (Maddi and Kobasa, 1984), sense of humour (Nezu et al., 1988), sense of coherence (Antonovsky, 1979), self-efficacy (Bandura, 1977), coping styles (Lazarus, 1999), social support (Cohen and Wills, 1985) and socio-economic status (Jenkins, 1991, cited in Crossley, 2000). These factors serve either to predispose the individual to experiencing stress, or to buffer against stress. They offer an explanation for individual differences in the experience of daily hassles, highlighting risk factors and potential areas for intervention.

\section{Individualistic focus of the daily hassles concept}

Undoubtedly the ability to identify risk factors and suggest interventions is a valuable outcome of the daily hassles research. However, what is clearly problematic with this approach is that the vast majority of these factors reside within the individual, reflecting the level of analysis of the research. With the exception of factors such as social support and socio-economic status, the majority of mediators and moderators can be understood to differentiate between different personality traits and states or perceptual styles. This individualistic focus is concerning because it characterizes daily hassles as a psychological or behavioural problem, thus diverting attention from the role of social, historical, cultural or political factors in the creation, exacerbation, reduction or prevention of stress in people's lives. Arguably, this overly individualistic focus is the product of the quantitative research methodology that has dominated daily hassles research. We will consider this point in more depth later.

\section{The absence of older people in daily hassles research}

Research has demonstrated a clear relationship between daily hassles and health and wellbeing, however, the majority of studies have been conducted with the general adult population (Balaam et al., 2001). The small number of studies conducted with older people has, however, continued to demonstrate this relationship, suggesting that daily hassles may be an important source of stress for the older population. For example, research by Murdock et al. (1998) found that negative small life events contributed over and above demographic factors, conjugal bereavement and major life events, to psychological distress in older people. Scheidt (1986) also identified various hassles of differing strength in different groups of older people. Mroczek and Almeida (2004) found a stronger association between daily hassles and negative affect in older adults as compared to younger adults. A meta-analysis of studies examining negative life events (including daily hassles) and depression in old age was conducted by Kraaij et al. (2002). Both negative life events and daily hassles were found to have a strong relationship to depression in older people. Finally, Landrevill and Vezina (1992) cited in Ruth and Coleman (1996) noted that daily hassles appear to have a stronger relationship to physical and psychological wellbeing than life events in older people. Although these studies support the assertion that daily hassles have significance for older people, it is clear that more research into the physical and social outcomes of daily hassles is required with this population to examine the phenomena further. Finally, no studies were identified that explored whether daily hassles are related to loss of independence in older people, as posited by the cumulative trivia hypothesis.

\section{Accumulation of daily hassles and their relationship to health}

Consistent with the cumulative trivia hypothesis a number of authors have asserted that daily hassles may accumulate over time, citing this as a particular risk to health or wellbeing. For example, the study by Kraaij et al. (2002) concluded that: 'special attention should be given to elderly people who 
have experienced an accumulation of stressful events and daily hassles, because they seem to be a group at greater risk' (p. 92, emphasis added). Lazarus (1999) also said of daily hassles that: 'especially when they pile up or touch on special areas of vulnerability ... they can be very stressful for some people and very important for their subjective wellbeing and physical health' (p. 57, emphasis added). We might ask to what extent the knowledge produced by the psychology domain has informed health and social care practice? For example, the extent to which the risk of an accumulation of daily hassles is identified by health and social care assessments of older people is questionable.

\section{The paucity of qualitative research into daily hassles}

As has already been noted, the daily hassles research has been dominated by quantitative methods with all of the studies outlined thus far having utilized this approach. Balaam et al. (2001) pointed to the over-abundance of quantitative designs as a weakness in the daily hassles literature, criticizing the failure to locate the concept within the experiences of older people. In the qualitative literature, one study was identified in which daily hassles featured. Godfrey et al. (2004) conducted an investigation into the experience of ageing in two areas in the north of England, with the aim of elucidating what constitutes 'a good life'. Their work consisted of 84 one-to-one interviews with people ranging in age from 58-97 based on a life history approach, 11 focus group interviews with 98 people in which a deeper understanding of life in older age and strategies for managing change were sought and 6 further focus group interviews with 58 people exploring service preferences and priorities. At one site older people and community staff members were actively involved in all aspects of the analysis and shaping of the report with the older people conducting half the individual interviews. The authors identified hassles as a major source of stress for many of the older people in their study, with a large variety of hassles indicated:

The constant reminders of the death of a spouse or close friend when faced with having to deal with the tasks which that person had previously undertaken; the myriad of little things that they could either not do, or found difficulty in doing, because of increasing disabilities - unscrewing jars, changing light bulbs, sweeping leaves from the gutters, putting up and taking down curtains, and cleaning windows ... the continuous challenge of having to resolve problems that were previously taken for granted - negotiating hilly and/ or uneven terrain and being able to sit down whilst out shopping; the worry of maintaining the fabric and decoration of their homes. The frustrations generated by these hassles were twofold: that in the absence of family, friends or neighbours there was no obvious source of help with them; and that they foreshadowed an escalation of dependence.

(Godfrey et al., 2004: 132)

Godfrey et al.'s findings are important because the account of hassles and their effects was grounded in the experiences described by older people themselves. Their quote demonstrates the wide variety of minor difficulties that older people face. Moreover, the emphasis on feelings of frustration and the portent of lost independence corroborate much of Hockey's hypothesis.

\section{Impact of the social and political context on daily hassles}

Two particularly salient points emerging from Godfrey et al.'s research are firstly, that older people may not perceive an obvious source of help with hassles, and secondly, that hassles 'foreshadowed an escalation of dependence'. The second point demonstrates the fear and worry that are concomitant with daily hassles, or 'trivia', such that they highlight to the older person their declining ability and progression toward dependence. It is notable that the fear of increasing dependence on others is intermingled with the difficulty some older people experienced in identifying sources of help. There appears to be an inherent contradiction between these points that highlights the complexity of how hassles are perceived and coped with: tackling threats to independence can necessitate some level of dependence on others. What is also salient is that both of these points draw attention to the importance of the social and political context. 
In the social context, health or social services that are widely available, easily accessed and targeted at the level where daily hassles or 'trivia' occur, may prevent their accumulation to a crisis. Such provision is contingent on the political context, requiring that older people are a political priority with policies in place to address their needs. The social context is also indicated at a more implicit level by the fear that older people have of dependence and the frustration that Godfrey et al.'s participants experienced in carrying out tasks that used to be dealt with easily. Embedded in these concerns are issues regarding identity and self-hood, as well as values attached to independence that might be understood to reflect social discourses of independence. We will explore this further at a later point.

A consideration of the daily hassles literature has clearly demonstrated the strong overlap between Hockey's hypothesis and this concept. An obvious question is therefore whether cumulative trivia should simply be subsumed within the established daily hassles framework, or whether it merits distinction from the latter as a concept in its own right or whether the daily hassles framework requires refinement in order to encapsulate Hockey's concept. Some key concerns about daily hassles have already been highlighted. We have noted that the concept is presently heavily individualistic in focus, contending that social, cultural, historical and political factors are largely absent. We have also noted our concern (Balaam et al., 2001) that the concept has rarely been examined in the older population, and that its research has been overly quantitative, thus failing to locate the concept within older people's experiences. Finally we have indicated facets of the social context that may have significance for whether and how daily hassles are experienced. On this basis we would argue that it is not possible to subsume cumulative trivia within the daily hassles framework.

\section{Using a social constructionist paradigm to define the need for a refinement of daily hassles}

Our critique of daily hassles is informed by the concerns of critical theory and social constructionism regarding positivism and quantitative research methods in the social sciences. In common with the general social sciences, the domain of health psychology from which daily hassles has originated has been subjected to strong critical enquiry in recent years (eg Crossley, 2000; Murray, 2004). Epistemological debates are beyond the scope of this article; however, two arguments from the critical approach are of relevance. Firstly, critical theorists such as Crossley (2000) and Stam (2000) have contended that quantitative methods are inappropriate to the study of social and psychological phenomena. They argue that the quantitative endeavour to simplify and reduce concepts into their component parts is misguided, such that they attempt to study phenomena in isolation from the context in which they naturally occur. The role of the social context is therefore absented from research findings, the result of which can be the pathologization of individuals. We have argued that this has been the case in the daily hassles research. Secondly, social constructionism asserts that social and psychological phenomena are discursively constructed, and that these discourses serve to constrain or enable certain ways of being in the world (Willig, 2002). The positivist underpinnings of the daily hassles research have meant that the impact of such discourses has not been considered.

Consistent with a critical approach, we would argue that cumulative trivia ought to be understood as the product of the complex interweaving between the physical, psychological, social, cultural and historical factors of older people's lives. The naturally occurring relationships between these factors should be recognized as mutually causative and reciprocal. How these factors interact to create, exacerbate, prevent or reduce cumulative trivia are questions that could be answered through qualitative research. Furthermore, qualitative research methods would enable the cumulative trivia concept to be explored and located within the experiences of older people (Balaam et al., 2001).

We have utilized this social constructionist framework to theorize about how the daily hassles framework as it currently stands cannot satisfactorily accommodate the concept of cumulative trivia. In order for this framework to be developed and refined we therefore propose that the following four research propositions be examined through appropriate research. Firstly, that cumulative daily hassles increase with age and lead to withdrawal from other activities. Secondly, daily hassles that become more common with age tend to be normalized through discourses of ageing and thereby 
trivialized. Thirdly, the accumulation of unresolved trivial daily hassles threatens the older individual's identity as a competent adult. Finally, the cumulative impact of daily hassles in later life leads to the loss of independence. We would highlight the centrality of independence to the cumulative trivia hypothesis, and would wish this concept to be explored as a social construction and from the perspective of older people. Further empirical and longitudinal research needs to be developed to examine these questions drawing on the pertinent points raised by the concept of cumulative trivia and located within the daily hassles framework.

\section{Should cumulative trivia be a distinct concept?}

Cumulative trivia differs from daily hassles in that the former, as conceived by Hockey, is conceptually specific to the older population, while the latter has been generally applied. An investigation of the four research propositions above on daily hassles would enable a description of 'trivia' that are associated with or specific to ageing and an opportunity to judge their distinctiveness or otherwise from the general population. We have provided examples of difficulties in conducting everyday tasks and activities that may result from declining function in older age, but which may not be typical in the general adult population. In addition, cumulative trivia would also include difficulties that are common to all populations, but whose significance may be greater for older people. For example, spilling a cup of coffee on the carpet might be a nuisance to a healthy adult, which incurs frustration or irritation. For an older person, however, the stress might be more acute because dealing with the problem requires utilizing precious energy that may prevent their engaging in other activities. The crucial issue is whether a distinct concept of cumulative trivia in relation to older people is useful either theoretically or socially. Theoretically further research is required to determine whether the daily hassles framework can be refined to accommodate the issues highlighted by cumulative trivia. Socially the question is whether a separate literature on cumulative trivia might fuel the ageist assumption that old age represents a different and distinct stage of life and as such is indicative of decline.

\section{Trivia in older people are normalized}

While everyday minor problems might be understood as exacerbated in older age, the converse may be said for some major problems. As we noted in our initial introduction to cumulative trivia, a key aspect of this concept is the way in which certain problems may be trivialized. In her own conception of cumulative trivia, Hockey included the repeated bereavements she had experienced as she got older. While the grief and pain of bereavement may be the same in older age as at any age, there is an extent to which old age incorporates an expectation of bereavement. The perception of bereavement as a normal part of ageing indicates how such experiences may be trivialized for older people (McCue, 1995).

A social constructionist reading might assert that repeated bereavement in older age normalizes this experience, thereby closing down possibilities for older people to express their grief. A number of difficulties associated with ageing, including declining function, might also be normalized in this way, creating similar difficulties for older people to express their feelings or to request help. Research that identifies and challenges these constructions provides an opportunity to challenge them through social change.

\section{Cumulative trivia linked to identity}

The daily hassles framework might benefit from a refinement based upon the concept of cumulative trivia through research exploring in greater depth the meaning that trivia hold for older people. Qualitative studies have indicated that the difficulties incurred by declining function in older age do not simply reflect the physical strain of carrying out minor tasks. These 'trivia' can, moreover, incur feelings of loss, regret or pain due to the ease with which they used to be conducted or dealt with. Tanner (2001: 262) found that for the older people in her study, tasks that incurred the greatest struggles were those: 'most closely linked with identity'. Clark et al. (1998) also found that everyday tasks such as housework, or cooking had particular significance to older people in maintaining their: 'public and private identities as competent adult members of their communities'. Whether or not trivia are felt to be stressful, and thus threaten 
independence, may therefore be dependent on their meaning to the older person and their relationship to identity.

\section{Cumulative trivia and independence}

The concept of cumulative trivia could also add to the refinement and development of daily hassles in relation to the concept of independence. Firstly, in contrast with daily hassles, cumulative trivia specifically postulates that loss of independence will occur in the absence of interruption or intervention for trivia. Secondly, as we alluded to earlier, the social construction of independence may be a particularly significant factor in the progression of cumulative trivia. Recent debates regarding the term 'independence' have argued that, firstly, it is poorly defined, and secondly, that it is inappropriately applied to the older population.

Secker et al. have critiqued the: 'dominant ideology of independence in the published literature' (Secker et al., 2003: 377). While the promotion of independence is a widespread goal for health and social care policy, the authors noted that the concept of independence is itself poorly defined. They have challenged the prevalent conceptualization of independence as the absence of dependence, with dependence conceptualized as a reliance on others to conduct everyday activities. The latter conceptualization is framed within the social and cultural context of western individualistic ideology, in which self-reliance is highly valued and esteemed, constituting an ideal state to be aspired to. The loss and decline in function that can accompany older age clearly conflicts with this ideal, because many older people will inevitably fall short of the ideal. Godfrey et al.'s (2004) assertion that trivia are particularly threatening because they 'foreshadow an escalation of dependence' may be taken to reflect the individualistic ideology. Dependence is therefore threatening because it involves burdening others:

Old people in this country have been influenced by the American ideal of independence and autonomy. The most important thing in the world is to be independent. So old people live alone, perhaps on the verge of starvation, in time without friends but we are independent ... It is a poor ideal and pursuing it does a great deal of harm ... We have reached the point where we think the only thing we can do for our children is to stay out of their hair ... So in the end older people have to devote their energies to 'not being a burden'.

(Mead, 1971, cited in Secker et al., 2003: 240-41)

Interventions focused on challenging and reconstructing the meaning of independence and how this is valued may serve to liberate older people from the pressure of avoiding dependence and the fear of being a burden. In this vein, the Older Person's Steering Group of the Joseph Rowntree Foundation (2004) have questioned the appropriateness of the term 'independence' for older people and suggested more appropriate terms such as 'interdependence', 'comfort' and 'a life worth living'. These terms serve to re-construct the ideal to one that can incorporate that degree of dependence that is required to maximise an older person's enjoyment of life. The present idealization of independence may be such as to inhibit older people from acknowledging their difficulties and seeking help. Re-constructing the ideal may therefore serve to legitimize these difficulties and liberate older people to ask for help.

Secker et al. (2003) proposed a new model in which dependence and independence were separated into two dimensions on a continuum from low to high. Dependence was defined as reliance on others, while independence was defined as: 'the individual's subjective assessment of whether their lived experience matches up to the desired level of choice, social usefulness and autonomy, which in turn depends on their psychological make-up, biography, social context and cultural heritage' (Secker et al., 2003: 381). By separating the two dimensions in this way, the model is able to account for the variety of possible meanings that independence can hold for older people, thus allowing an individual with a high degree of dependence upon others to feel independent, and likewise for an individual to have a low degree of dependence but to experience little sense of independence.

Evidently there are multiple possible meanings of 'independence' that need to be considered within our conceptualization of cumulative trivia. For some older people, independence refers to their ability to exercise choice and control and the feeling that they are socially useful. The accumulation of trivial difficulties may prevent such older people from feeling independent, because the effort

Primary Health Care Research and Development 2006; 7: 331-340 
involved in negotiating 'trivia' leaves little energy to do the things that they enjoy or value. Researchers have repeatedly highlighted that services offering 'that bit of help' with everyday tasks such as cleaning or shopping, enable older people to feel independent, because they free up time and energy for valued activities (eg Clark et al., 1998; Raynes et al., 2001; Newall et al., 2005). Moreover, Clark et al. have noted that older people's perceptions of independence are fluid, shifting in line with changing capacities. Thus, where certain activities or tasks are no longer manageable, these can be given up without threatening independence, so long as the core of independence can be retained; that is, choice and control. As we have already noted, the implementation of such interventions is dependent upon social and political motivation.

\section{Conclusions}

We have sought in this article to describe the cumulative trivia concept and to call attention to the potentially major significance of minor problems in older age. We have utilized the social constructionist paradigm to critically examine the daily hassles literature and to explore how the concept of cumulative trivia might usefully represent added value to this framework. We have posed the question whether the concept of cumulative trivia can be subsumed within daily hassles, whether it represents a concept in its own right or whether daily hassles requires refinement to encapsulate the characteristics of cumulative trivia. Our examination has indicated that the last option may be achieved through a broadening of the focus of daily hassles so that causal responsibility for cumulative trivia is located in the social, political, cultural and individual domains. This is in contrast with the current strongly individualistic focus of daily hassles.

Our focus on the social context has led us to argue that cumulative trivia may be strongly impacted by social constructions of ageing and independence. We have suggested that problems of older age are normalized and trivialized, and that the ideology of independence presents an unattainable goal for older people; thus setting them up for failure. We have also noted that the provision of services to address 'trivia' may serve to prevent their accumulation to a crisis point. What is indicated, however, is that the social context may have vital importance to the onset or exacerbation of cumulative trivia. As a population, older people have been subject to various forms of discrimination, including the low priority they have been given in the provision of health and social services (Clark et al., 1998; Tanner, 2001). In a society where support and help is widely available to address minor problems in old age, and where the prevailing ideology supports reciprocity and interdependence, cumulative trivia might not exist. It is possible therefore, that cumulative trivia is a product of health and social inequalities related to age. Research is clearly required to investigate the credibility of these suggestions.

\section{Acknowledgements}

This article comes directly from the ideas and intellectual property of Lisbeth Hockey and is written in her memory (Dr Lisbeth Hockey, 1918-2004).

We would also like to acknowledge the financial support which the Queen's Nursing Institute, Scotland provided for the initial literature review conducted in 2001. A number of authors have contributed significantly to the production of this article. Lisbeth Hockey first conceived of the cumulative trivia concept in a personal communication to staff at the Queen's Nursing Institute, Scotland. Elinor Newall carried out the most recent literature review in 2005 and wrote the present article. Belinda Dewar supervised Elinor Newall and critically revised this article. Alan Gilloran was responsible for the final edit and incorporation of the reviewers' helpful suggestions. Marti Balaam, Mike Porter, Sarah Baggaley, Belinda Dewar, Lisbeth Hockey and Scott Murray played key roles in conducting and writing the original literature review and in conducting the exploratory focus group work in 2001. The report of this work is available at www.qmuc.ac.uk/opa.

\section{References}

Antonovsky, A. 1979: Health, stress and coping: new perspectives on mental and physical wellbeing. New York: Jossey-Bass.

Balaam, M., Porter, M., Baggaley, S., Dewar, B., Hockey, L. and Murray, S. 2001: Cumulative trivia: a literature review. Unpublished Report. Royal Bank of Scotland Centre for the Older Person's Agenda (available at www.qmuc.ac.uk/opa), Queen Margaret University College and Department of 
Community Health Sciences, General Practice, University of Edinburgh.

Bandura, A. 1977: Self-efficacy: toward a unifying theory of behavior change. Psychological Review 84, 191-215.

Clark, H., Dyer, S. and Horwood, J. 1998: 'That bit of help': the high value of low level preventive services for older people. Bristol: Policy Press/Joseph Rowntree Foundation.

Cohen, S. and Wills, T. 1985: Stress, social support and the buffering hypothesis. Psychological Bulletin 98, 310-57.

Crossley, M. 2000: Rethinking health psychology. Buckingham: Open University Press.

Godfrey, M., Townsend, J. and Denby, T. 2004: Building a good life for older people in local communities. Bristol: Policy Press/Joseph Rowntree Foundation.

Hockey, L. 1999: Personal communication. Edinburgh: Queen's Nursing Institute.

Holmes, T. and Rahe, R. 1967: The social readjustment rating scale. Journal of Psychosomatic Research 4, 189-94.

Joseph Rowntree Foundation Older People's Steering Group. 2004: Older people shaping policy and practice. York: Joseph Rowntree Foundation.

Kanner, A., Coyne, J., Schaefer, C. and Lazarus, R. 1980: Comparison of two modes of stress measurement: daily hassles and uplifts versus major life events. Journal of Behavioral Medicine 4, 1-39.

Kraaij, V., Arensman, E. and Spinhoven, P. 2002: Negative life events and depression in elderly persons: a meta-analysis. Journal of Gerontology: Psychological Sciences 57B, 87-94.

Lazarus, R. 1999: Stress and emotion: a new synthesis. London: Free Association Books.

Maddi, S.R. and Kobasa, S.C. 1984: The hardy executive: health under stress. Homewood, IL: Dow Jones Irwin.

McCue, J.D. 1995: The naturalness of dying. Journal of the American Medical Association 273, 1039-43.

Monroe, S. 1983: Major and minor life events as predictors of psychological distress: further issues and findings. Journal of Behavioral Medicine 6, 189-205.

Mroczek, D. and Almeida, D. 2004: The effect of daily stress, personality and age on daily negative affect. Journal of Personality 72, 355-78.

Murdock, M.E., Guarnaccia, C.A., Hayslip, B. and Mckibbin, C.L. 1988: The contribution of small life events to the psychological distress of married and widowed older women. Journal of Women and Ageing 10, 3-22.
Murray, M. 2004: Critical health psychology. New York: Palgrave Macmillan.

Newall, E., Gilloran, A., O'May, F. and Donaldson, C. 2005: External evaluation of the Dumfries and Galloway better neighbourhood services fund (BNSF) vulnerable older people's pathfinder: final report. Queen Margaret University College, Edinburgh (http://www.qmuc.ac.uk/opa/). Royal Bank of Scotland Centre for the Older Person's Agenda.

Nezu, A., Nezu, C. and Blisset, S. 1988: Sense of humor as a moderator of the relation between stressful events and psychological distress: a prospective analysis. Journal of Personality and Social Psychology 54, 520-25.

Raynes, N., Temple, B., Glenister, C. and Coulthard, L. 2001: Quality at home for older people: involving service users in defining home care specifications. Bristol: The Policy Press/Joseph Rowntree Foundation.

Rowlinson, R. and Felner, R. 1988: Major life events, hassles, and adaptation in adolescence: confounding in the conceptualisation and measurement of life stress and adjustment revisited. Journal of Personality and Social Psychology 55, 432-44.

Ruth, J. and Coleman, P. 1996: Personality and ageing: coping and management of the self in later life. In Birren, J. and Schaie, K., editors, Handbook of the psychology of aging, fourth edition. San Diego: Academic Press.

Scheidt, R.J. 1986: Daily hassles and profiles of well-being among older residents of small rural towns. Psychological Reports 58, 587-90.

Secker, J, Hill, R., Villeneau, L. and Parkman, S. 2003: Promoting independence: but promoting what and how? Ageing and Society 23, 375-91.

Stam, H. 2000: Theorizing health and illness: functionalism, subjectivity and reflexivity. Journal of Health Psychology 5, 273-83.

Stevenson, O. 1989: Age and vulnerability: a guide to better care. London: Edward Arnold.

Tanner, D. 2001: Sustaining the self in later life: supporting older people in the community. Ageing and Society 21, 255-78.

Willig, C. 2002: A discourse-dynamic approach to the study of subjectivity in health psychology. In Marks, D., editor, The health psychology reader. London: Sage. 